\title{
Analysis of Entropy Generation in Flow of Methanol-Based Nanofluid in a Sinusoidal Wavy Channel
}

\author{
Muhammad Qasim ${ }^{1}$, Zafar Hayat Khan ${ }^{2}$, Ilyas Khan ${ }^{3}$ and Qasem M. Al-Mdallal ${ }^{4, *}$ \\ 1 Department of Mathematics, COMSATS Institute of Information Technology, Park Road, Chak Shahzad, \\ Islamabad 44000, Pakistan; mq_qau@yahoo.com \\ 2 Department of Mathematics, University of Malakand, Khyber Pakhtunktwo 18800, Pakistan; \\ zafarhayyatkhan@gmail.com \\ 3 Department of Mechanical and Industrial Engineering, College of Engineering, Majmaah University, \\ Majmaah 11592, Saudi Arabia; i.said@mu.edu.sa \\ 4 Department of Mathematical Sciences, United Arab Emirates University, Al Ain 15551, UAE \\ * Correspondence: q.almdallal@uaeu.ac.ae
}

Received: 24 April 2017; Accepted: 14 July 2017; Published: 8 October 2017

\begin{abstract}
The entropy generation due to heat transfer and fluid friction in mixed convective peristaltic flow of methanol- $\mathrm{Al}_{2} \mathrm{O}_{3}$ nano fluid is examined. Maxwell's thermal conductivity model is used in analysis. Velocity and temperature profiles are utilized in the computation of the entropy generation number. The effects of involved physical parameters on velocity, temperature, entropy generation number, and Bejan number are discussed and explained graphically.
\end{abstract}

Keywords: second law analysis; peristaltic transport; methanol based nanofluid; asymmetric channel

\section{Introduction}

In the past, much attention has been given to peristalsis caused by sinusoidal waves in channels/tubes. Prominent processes involving peristalsis include chyme movement in the gastrointestinal tract, blood circulation in small blood vessels, urine transport from the kidney to bladder, spermatozoa transport in the ductus efferent of the male reproductive tract, sanitary and corrosive fluids transport, blood pumps in a heart-lung machine, and many others. Numerous experimental and theoretical studies have been performed after the seminal experimental work on peristalsis of viscous fluid by Latham [1]. The theoretical attempt by Shapiro [2] showed excellent agreement with the experimental study [1]. Afterwards, extensive attempts have been made on the topic. Some recent studies in this direction can be consulted in References [3-10].

The study of nanofluids has received much attention from researchers in the past. The study of heat transfer in the presence of nanofluids is of great practical significance in many branches of engineering and medical sciences. Nanofluid is a liquid in which nanometer-sized particles (called nanoparticles) made up of metals, carbides, oxides, or carbon nanotubes are suspended in the conventional fluid, such as oils, water, ethylene glycol, etc. Choi [11] experimentally found that the addition of these nanoparticles in the traditional fluid significantly enhances the thermal conductivity of the fluid. Literature concerning the flow of nanofluids may be found in the recent book by Minkowycz et al. [12]. The peristaltic transport of nanoparticles has applications in the treatment of malignant tumors, magnetic resonance imaging to diagnose bleeding reduction during diseases, in cancer therapy, and in the transport of drugs. In view of this, important contributions of peristaltic transport of nanofluids have been studied [13-22].

Entropy generation is a measure of irreversibility associated with heat transfer processes. The study of entropy generation within the system is significant, as it helps to trace the sources 
which destroys available energy. Therefore, by knowing these factors or sources, one can minimize the entropy to preserve the quality of energy for the optimal design of any thermal system. At present, the research topic of entropy generation minimization has acquired special status amongst scientists worldwide. They are re-examining all energy consuming, converting, and producing systems and developing new techniques in order to remove all sources that destroy the available work. Improved economics are being proposed around the world to more accurately preserve the present energy supply shortage [23-34]. Soudi et al. [35] investigated the entropy generation rate in a peristaltic pump. They analyzed that peristalsis is a great entropy generator process, due essentially to dynamic irreversibility. Some more interesting studies in this direction can be consulted in References [36-39]. Existing literature witnesses that no attention is focused so far on the study of entropy generation on mixed convection [9,40-44] peristaltic flow in the presence of nanoparticles. In this study, the entropy generation due to heat transfer and fluid friction in peristaltic flow of methanol- $\mathrm{Al}_{2} \mathrm{O}_{3}$ nano fluid is examined. Analysis is performed under long wavelength and low Reynold's number approximations. Maxwell's thermal conductivity model is used in analysis. The effects of involved physical parameters are discussed and explained graphically.

\section{Problem Formulation}

Consider the flow of a nanofluid in an asymmetric channel of width $d_{1}+d_{2}$. The flow within the channel is induced due to the propagation of sinusoidal waves of wavelength $\lambda$ travelling at the channel walls with constant speed $c$. Cartesian coordinates $(\bar{X}, \bar{Y})$ system is taken in such a way that the $\bar{X}$-axis lies along the length of channel and the $\bar{Y}$-axis lies normal to it (see Figure 1). The geometry of the peristaltic walls can be expressed in the form:

$$
\begin{gathered}
\bar{h}_{1}(\bar{X}, \bar{t})=\bar{d}_{1}+\bar{a}_{1} \cos \left(\frac{2 \pi}{\lambda}(\bar{X}-c \bar{t})\right), \\
\bar{h}_{2}(\bar{X}, \bar{t})=-\bar{d}_{2}-\bar{a}_{2} \cos \left(\frac{2 \pi}{\lambda}(\bar{X}-c \bar{t})+\gamma\right),
\end{gathered}
$$

where $\bar{h}_{1}(\bar{X}, \bar{t})$ and $\bar{h}_{2}(\bar{X}, \bar{t})$ are the walls in the regions $\bar{Y}>0$ and $\bar{Y}<0$, respectively. $\bar{a}_{1}, \bar{a}_{2}$ are the wave amplitudes travelling along $\bar{h}_{1}(\bar{X}, \bar{t})$ and $\bar{h}_{2}(\bar{X}, \bar{t})$, respectively. $\gamma$ is the phase difference, $\lambda$ is the wavelength and $\bar{t}$ is the time. Further, $\bar{a}_{1}, \bar{a}_{2}, \bar{d}_{1}, \bar{d}_{2}$ and $\gamma$ satisfy $\bar{a}_{1}^{2}+\bar{a}_{2}^{2}+2 \bar{a}_{1} \bar{a}_{2} \cos \gamma \leq\left(\bar{d}_{1}+\bar{d}_{2}\right)^{2}$. For the velocity components $\bar{U}$ along the $\bar{X}$ and $\bar{V}$ along the $\bar{Y}$ - directions in the fixed frame, one can write $\mathbf{V}$ as:

$$
\mathbf{V}=[\bar{U}(\bar{X}, \bar{Y}, \bar{t}), \bar{V}(\bar{X}, \bar{Y}, \bar{t}), 0],
$$

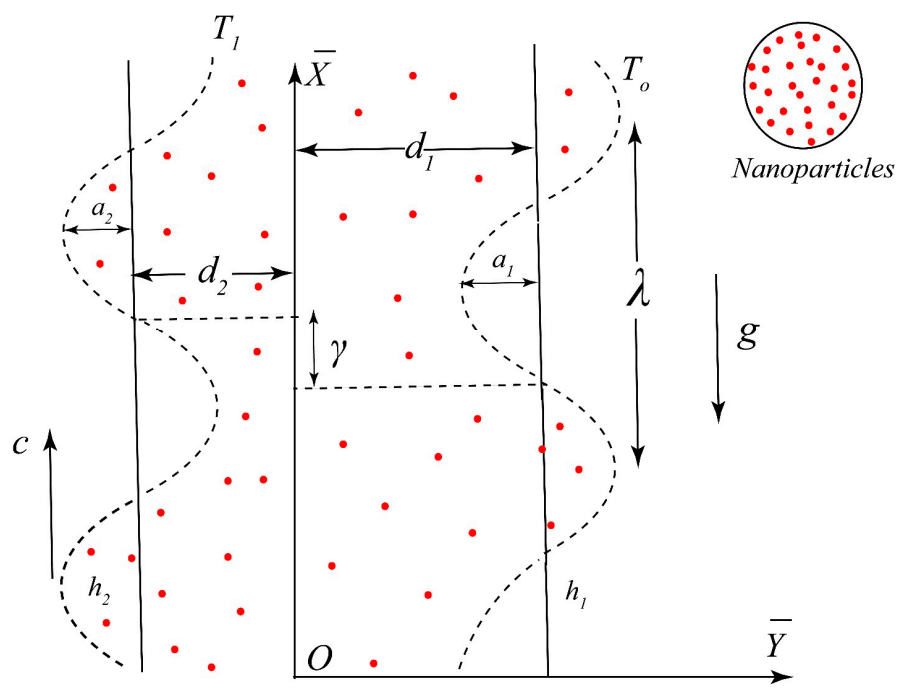

Figure 1. Geometry of the problem. 
The law of conservation of mass, momentum, and energy can be written as $[16,37,43,44]$ :

$$
\begin{gathered}
\frac{\partial \bar{U}}{\partial \bar{X}}+\frac{\partial \bar{V}}{\partial \bar{Y}}=0 \\
\rho_{e f f}\left(\frac{\partial \bar{U}}{\partial \bar{t}}+\bar{U} \frac{\partial \bar{U}}{\partial \bar{X}}+\bar{V} \frac{\partial \bar{U}}{\partial \bar{Y}}\right)=-\frac{\partial \bar{P}}{\partial \bar{X}}+\mu_{e f f}\left(\frac{\partial^{2} \bar{U}}{\partial \bar{X}^{2}}+\frac{\partial^{2} \bar{U}}{\partial \bar{Y}^{2}}\right)+g(\rho \beta)_{e f f}\left(T_{1}-T_{0}\right), \\
\rho_{e f f}\left(\frac{\partial \bar{V}}{\partial \bar{t}}+\bar{U} \frac{\partial \bar{V}}{\partial \bar{X}}+\bar{V} \frac{\partial \bar{V}}{\partial \bar{Y}}\right)=-\frac{\partial \bar{P}}{\partial \bar{Y}}+\mu_{e f f}\left(\frac{\partial^{2} \bar{V}}{\partial \bar{X}^{2}}+\frac{\partial^{2} \bar{V}}{\partial \bar{Y}^{2}}\right), \\
(\rho C)_{e f f}\left[\frac{\partial T}{\partial \bar{t}}+\bar{U} \frac{\partial T}{\partial \bar{X}}+\bar{V} \frac{\partial T}{\partial \bar{Y}}\right] \\
=K_{e f f}\left(\frac{\partial^{2} T}{\partial \bar{X}^{2}}+\frac{\partial^{2} T}{\partial \bar{Y}^{2}}\right)+\mu_{e f f}\left[2\left(\frac{\partial \bar{U}}{\partial \bar{X}}\right)^{2}+2\left(\frac{\partial \bar{V}}{\partial \bar{Y}}\right)^{2}+\left(\frac{\partial \bar{U}}{\partial \bar{Y}}+\frac{\partial \bar{V}}{\partial \bar{X}}\right)^{2}\right] .
\end{gathered}
$$

In the above equations, the effective density $\rho_{e f f}$, effective viscosity $\mu_{e f f}$, effective heat capacity $C_{e f f}$, thermal conductivity $K_{e f f}$, and effective thermal expansion coefficient $(\rho \beta)_{e f f}$ of the nanofluid for a two-phase model are taken in the form [12]:

$$
\begin{aligned}
& \rho_{e f f}=(1-\phi) \rho_{f}+\phi \rho_{p},(\rho C)_{e f f}=(1-\phi)(\rho C)_{f}+\phi(\rho C)_{p}, \\
& (\rho \beta)_{e f f}=(1-\phi)(\rho \beta)_{f}+\phi(\rho \beta)_{p^{\prime}} \\
& \frac{K_{e f f}}{K_{f}}=\frac{K_{p}+2 k_{f}+2 \phi\left(K_{f}-K_{p}\right)}{K_{p}+2 k_{f}-\phi\left(K_{f}-K_{p}\right)}, \mu_{e f f}=\frac{\mu_{f}}{(1-\phi)^{2.5}},
\end{aligned}
$$

Introducing the transformations between fixed $(\bar{X}, \bar{Y})$ and wave frames $(\bar{x}, \bar{y})$ :

$$
\bar{x}=\bar{X}-c \bar{t}, \bar{y}=\bar{Y}, \bar{u}(\bar{x}, \bar{y})=\bar{U}-c, \bar{v}(\bar{x}, \bar{y})=\bar{V}, \bar{p}(\bar{x}, \bar{y})=\bar{P}(\bar{X}, \bar{Y}, \bar{t}),
$$

the fundamental Equations (3)-(6) in wave frame become:

$$
\begin{gathered}
\frac{\partial \bar{u}}{\partial \bar{x}}+\frac{\partial \bar{v}}{\partial \bar{y}}=0 \\
\left((1-\phi) \rho_{f}+\phi \rho_{p}\right)\left((\bar{u}+c) \frac{\partial \bar{u}}{\partial \bar{x}}+\bar{v} \frac{\partial \bar{u}}{\partial \bar{y}}\right)=-\frac{\partial \bar{p}}{\partial \bar{x}}+\frac{\mu_{f}}{(1-\phi)^{2.5}}\left(\frac{\partial^{2} \bar{u}}{\partial \bar{x}^{2}}+\frac{\partial^{2} \bar{u}}{\partial \bar{y}^{2}}\right) \\
+g\left((1-\phi)(\rho \beta)_{f}+\varphi(\rho \beta)_{p}\right)\left(T-T_{0}\right) \\
\left((1-\phi) \rho_{f}+\phi \rho_{p}\right)\left((\bar{u}+c) \frac{\partial \bar{v}}{\partial \bar{x}}+\bar{v} \frac{\partial \bar{v}}{\partial \bar{y}}\right)=-\frac{\partial \bar{p}}{\partial \bar{y}}+\frac{\mu_{f}}{(1-\phi)^{2.5}}\left(\frac{\partial^{2} \bar{v}}{\partial \bar{x}^{2}}+\frac{\partial^{2} \bar{v}}{\partial \bar{y}^{2}}\right) \\
(1-\phi)(\rho C)_{f}+\phi(\rho C)_{p}\left[(\bar{u}+c) \frac{\partial T}{\partial \bar{x}}+\bar{v} \frac{\partial T}{\partial \bar{y}}\right]=K_{e f f}\left[\frac{\partial^{2} T}{\partial \bar{x}^{2}}+\frac{\partial^{2} T}{\partial \bar{y}^{2}}\right] \\
+\frac{\mu_{f}}{(1-\phi)^{2.5}}\left[2\left(\frac{\partial \bar{u}}{\partial \bar{x}}\right)^{2}+2\left(\frac{\partial \bar{v}}{\partial \bar{y}}\right)^{2}+\left(\frac{\partial \bar{u}}{\partial \bar{y}}+\frac{\partial \bar{v}}{\partial \bar{x}}\right)^{2}\right]
\end{gathered}
$$

Defining the following dimensionless quantities:

$$
\begin{aligned}
& x=\frac{\bar{x}}{\lambda}, u=\frac{\bar{u}}{c}, y=\frac{\bar{y}}{d_{1}}, v=\frac{\bar{v}}{c \delta}, \delta=\frac{d_{1}}{\lambda}, \quad p=\frac{d_{1}^{2} \bar{p}}{\mu c \lambda}, \quad h_{1}=\frac{\bar{h}_{1}}{d_{1}}, \quad h_{2}=\frac{\bar{h}_{2}}{d_{1}}, \\
& a=\frac{a_{1}}{d_{1}}, \quad d=\frac{d_{2}}{d_{1}}, \quad b=\frac{b_{1}}{d_{1}}, \quad \operatorname{Re}=\frac{\rho_{f} c d_{1}}{\mu_{f}}, \bar{\Psi}=\frac{\Psi}{c d_{1}}, \theta=\frac{T-T_{0}}{T_{1}-T_{0}}, \\
& \operatorname{Pr}=\frac{\mu_{f} C_{f}}{K_{f}}, E c=\frac{c^{2}}{C_{f}\left(T_{1}-T_{0}\right)}, \quad B r=\operatorname{Pr} E c, G r=\frac{\rho_{f} \beta_{f} g d_{1}^{2}\left(T_{1}-T_{0}\right)}{\mu_{f} c} \\
& u=\frac{\partial \Psi}{\partial y}, \quad v=-\delta \frac{\partial \Psi}{\partial x},
\end{aligned}
$$

where $\Psi, \operatorname{Re}, \operatorname{Pr}, E c, B r, G r$ respectively, are the stream function, the Reynolds number, the Prandtl number, the Eckert number, the Brinkman number, and the Grashof number. In terms of these 
dimensionless quantities and in view of long wavelength and low Reynolds number approximations, Equations (10)-(12) are reduced in the following forms:

$$
\begin{gathered}
\frac{\partial p}{\partial x}=\frac{1}{(1-\phi)^{2.5}} \frac{\partial^{3} \Psi}{\partial y^{3}}+\left[1-\phi+\phi \frac{(\rho \beta)_{p}}{(\rho \beta)_{f}}\right] \operatorname{Gr} \theta, \\
\frac{\partial p}{\partial y}=0
\end{gathered}
$$

From (14) and (15) we have:

$$
\begin{gathered}
\frac{1}{(1-\phi)^{2.5}} \frac{\partial^{4} \Psi}{\partial y^{4}}+\left[1-\phi+\phi \frac{(\rho \beta)_{p}}{(\rho \beta)_{f}}\right] G r \frac{\partial \theta}{\partial y}=0 \\
{\left[\frac{K_{p}+2 K_{f}+2 \phi\left(K_{f}-K_{p}\right)}{K_{p}+2 K_{f}-\phi\left(K_{f}-K_{p}\right)}\right] \frac{\partial^{2} \theta}{\partial y^{2}}+\frac{B r}{(1-\phi)^{2.5}}\left(\frac{\partial^{2} \Psi}{\partial y^{2}}\right)^{2}=0 .}
\end{gathered}
$$

The dimensionless boundary conditions are defined by:

$$
\begin{gathered}
\Psi=\frac{F}{2}, \frac{\partial \Psi}{\partial y}=-1, \theta=0, \text { at } y=h_{1}, \\
\Psi=-\frac{F}{2}, \frac{\partial \Psi}{\partial y}=-1, \theta=1, \text { at } y=h_{2} .
\end{gathered}
$$

where the dimensionless walls surfaces are given by:

$$
y=h_{1}=1+a \cos (2 \pi x), \quad y=h_{2}=-d-b \cos (2 \pi x+\gamma) .
$$

Time mean flow rate $F$ in the wave frame is related to the dimensionless time mean flow rate $Q$ in the laboratory frame by:

$$
Q=F+1+d, \quad F=\int_{h_{2}}^{h_{1}} \frac{\partial \Psi}{\partial y} d y
$$

The pressure rise $\Delta P_{\lambda}$ is defined as:

$$
\Delta P_{\lambda}=\int_{0}^{1} \frac{d p}{d x} d x
$$

Heat transfer coefficients at the walls are given by:

$$
Z_{1}=\left.h_{1 x} \frac{\partial \theta}{\partial y}\right|_{y=h_{1}}, Z_{2}=\left.h_{2 x} \frac{\partial \theta}{\partial y}\right|_{y=h_{2}} .
$$

\section{Entropy Generation Analysis}

The entropy generation number $N_{S}$ in dimensionless form [36-39] is given by:

$$
N_{S}=\left[\frac{K_{p}+2 K_{f}+2 \phi\left(K_{f}-K_{p}\right)}{K_{p}+2 K_{f}-\phi\left(K_{f}-K_{p}\right)}\right]\left(\frac{\partial \theta}{\partial y}\right)^{2}+\frac{B r}{\Omega(1-\phi)^{2.5}}\left(\frac{\partial^{2} \Psi}{\partial y^{2}}\right)^{2},
$$

where $\Omega=\Delta T / T_{0}$ is the dimensionless temperature difference and the product of the Brickman number $B r$, and the inverse of the dimensionless temperature difference $\Omega^{-1}$ is the viscous dissipation parameter $\left(B r \Omega^{-1}\right)$. The expression in Equation (23) can be written as the sum of entropy generation due to heat transfer $\left(N_{H}\right)$ and local entropy generation due to fluid friction irreversibility $\left(N_{F}\right)$.

$$
N_{S}=N_{H}+N_{F}
$$


In order to determine whether heat transfer irreversibility dominates over fluid friction or vice versa, the irreversibility distribution ratio $\Phi$ is defined as [26-30]:

$$
\Phi=\frac{\text { Fluid friction irreversibility }}{\text { Irreversibility due to heat transfer }}=\frac{N_{F}}{N_{H}}
$$

In the range $0<\Phi<1$, the heat transfer irreversibility dominates, whereas $\Phi>1$ indicates that irreversibility is only due to fluid friction. Both the heat transfer and fluid friction have the same contribution to entropy generation when $\Phi=1$. An alternative irreversibility ratio, known as the Bejan number, is the ratio of heat transfer irreversibility to the total irreversibility due to heat transfer and fluid friction. It is given as [26-30]:

$$
B e=\frac{N_{H}}{N_{S}}=\frac{1}{1+\Phi}
$$

The Bejan number takes the values from 0 to 1 . Here, $B e=0$ is the limit at which irreversibility is dominated by fluid friction effects, and $B e=1$ is the opposite limit at which heat transfer irreversibility dominates. $B e=0.5$ is the case where fluid flow irreversibility and heat transfer irreversibility are of equal importance.

\section{Results and Discussion}

The resulting coupled nonlinear differential Equations (16) and (17) subject to the boundary conditions (18) were solved numerically using Mathematica built-in numerical solve NDSolve. The step-size is taken as 0.01 , and the accuracy to the fifth decimal place is regarded as the criterion of convergence.

This section seeks the influence of various physical parameters on axial velocity distribution $u$, axial pressure gradient $d p / d x$, pressure rise per wavelength $\Delta P_{\lambda}$, and temperature $\theta$. Further, the silent characteristics of the dimensionless entropy generation number $N s$ and the Bejan number $B e$ are explored explicitly. These pumping, heating, trapping, and entropy generation characteristics are explained through Figures 2-8. The thermophysical properties of the base fluid and considered nanoparticle are listed in Table 1.

The effect of the nanoparticle volume fraction $\phi$ and the Grashof number $G r$ on axial velocity is shown in Figure 2 for $\mathrm{Al}_{2} \mathrm{O}_{3}$ - Methanol nanofluid. It is observed that the maximum velocity decreases by increasing the nanoparticle volume fraction. A significant increase in the velocity is also noticed for large values of the Grashof number $G r$. This is due to the fact that increasing values of the Grashof number $G r$ make the buoyancy force stronger, thus increasing the velocity. Figure $2 b$ shows that the axial velocity distribution also increases by increasing the Brinkman number. Figure $3 a, b$ depict the effects of the Grashof number $G r$ and Brinkman number $B r$, respectively, on pressure rise versus flow rate. An increase in the Brinkman number causes an increase in the pressure rise in the pumping region, however, in the co-pumping region, the pumping rate decreases by increasing the Brinkman number. The addition of nanoparticles increases the pressure rise in the peristaltic pumping region. The Grashof number has similar effects on the pressure rise when compared with the Brinkman number. From Figure 4, it is noted that adding nanoparticles causes an increase in the resistance to fluid motion as a result of the increasing values of the pressure gradient. Further, it is observed that the magnitude of $d p / d x$ increases when the value of the Grashof number is increased. Further, these figures illustrate that in the wider part of channel, the pressure gradient is small and flow can easily pass through without the application of a large pressure gradient. On the other hand, in the narrow part of the channel, a large pressure gradient is required to maintain the same flux to pass through it. Trapping is another motivating sensation of peristalsis which is the formulation of an internally circulating bolus of fluid which moves along with the wave. Trapping fails to occur if a significant volume of the fluid is not flowing per unit time. The trapping phenomenon is shown in Figure $5 \mathrm{a}-\mathrm{c}$ for different values of the Grashof number. From these figures, it is observed that the 
trapped bolus size decreases when the Grashof number increases. The effects of the nanoparticle volume fraction, Grashof number, and Brinkman number on the temperature are analyzed through Figure $6 a, b$. The addition of nanoparticles and an increasing nanoparticle volume fraction reduces the temperature. An increase in the fluid temperature is observed when the Grashof number is increased. The Brinkman number has similar effects on the temperature of the nanofluid as compared to the Grashof number. Entropy generation attains high values near the channel walls and minimum values near the centerline of the channel (See Figure 7). By increasing the Grashof number, the total entropy generation increases near the walls (Figure 7a). Physically, this is due to the fact that by increasing the Grashof number, heat transfer due to convection facilitates the flow velocity and therefore the entropy generation. Figure $7 \mathrm{~b}$ illustrates the effect of the viscous dissipation number and the entropy generation number. As the viscous dissipation number $B r \Omega^{-1}$ increases, the entropy generation number increases. This is due to the fact that an increase in $B r \Omega^{-1}$ increases the entropy generation due to fluid friction. From Figure 8, as expected, the Bejan number has maximum values near the centerline of the channel and minimum values near the channel walls. The addition of nanoparticles and with an increase of nanoparticle volume fraction causes the Bejan number to increase. Table 2 shows that the heat transfer coefficient at both walls increases by increasing the Brinkman number. Heat transfer coefficient at right wall decreases by increasing the Grashof number, whereas an opposite behavior is noticed for left wall of the channel.

Table 1. Thermophysical properties of methanol and $\mathrm{Al}_{2} \mathrm{O}_{3}$.

\begin{tabular}{ccc}
\hline \multirow{2}{*}{ Physical Properties } & Base Fluid & Nanoparticles \\
\cline { 2 - 3 } & Methanol & $\mathbf{A l}_{2} \mathbf{O}_{3}$ \\
\hline$\rho\left(\mathrm{kg} / \mathrm{m}^{3}\right)$ & 792 & 3970 \\
\hline$c_{p}(\mathrm{~J} / \mathrm{kg} \mathrm{K})$ & 2545 & 765 \\
\hline$k(\mathrm{~W} / \mathrm{m} \mathrm{K})$ & 0.2035 & 40 \\
\hline
\end{tabular}

Table 2. Heat transfer coefficients at both walls when $x=0.1, \phi=0.2$.

\begin{tabular}{ccccccc}
\hline \multirow{2}{*}{$\boldsymbol{r}$} & \multicolumn{3}{c}{$Z_{\mathbf{1}}$} & \multicolumn{3}{c}{$Z_{\mathbf{2}}$} \\
\cline { 2 - 7 } & $\mathbf{G} \boldsymbol{r}=\mathbf{0 . 0}$ & $\mathbf{G r}=\mathbf{0 . 5}$ & $\mathbf{G r}=\mathbf{1 . 0}$ & $\mathbf{G r}=\mathbf{0 . 0}$ & $\mathbf{G r}=\mathbf{0 . 5}$ & $\mathbf{G r}=\mathbf{1 . 0}$ \\
\hline 0.5 & 0.69963 & 0.69366 & 0.68781 & 0.54627 & 0.55576 & 0.56547 \\
\hline 1 & 1.22518 & 1.21324 & 1.20158 & 1.36309 & 1.38209 & 1.40161 \\
\hline 2 & 2.27628 & 2.25248 & 2.22945 & 2.99672 & 3.03494 & 3.07455 \\
\hline
\end{tabular}
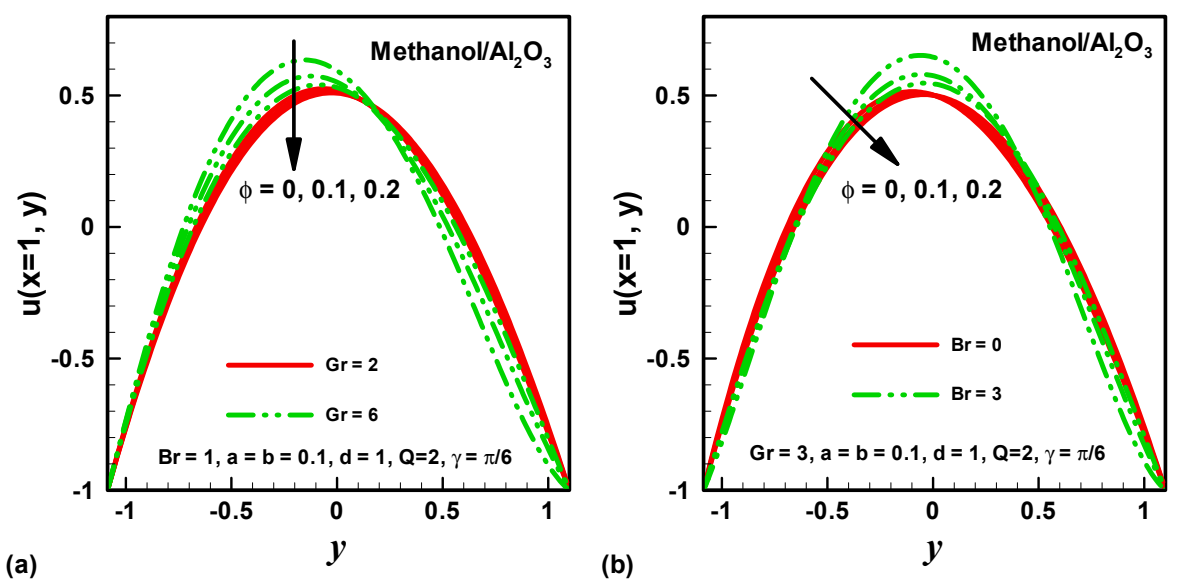

Figure 2. The axial velocity $u$ versus $y$ for different values of (a) the Grashof number $G r$; (b) the Brinkman number $\mathrm{Br}$. 

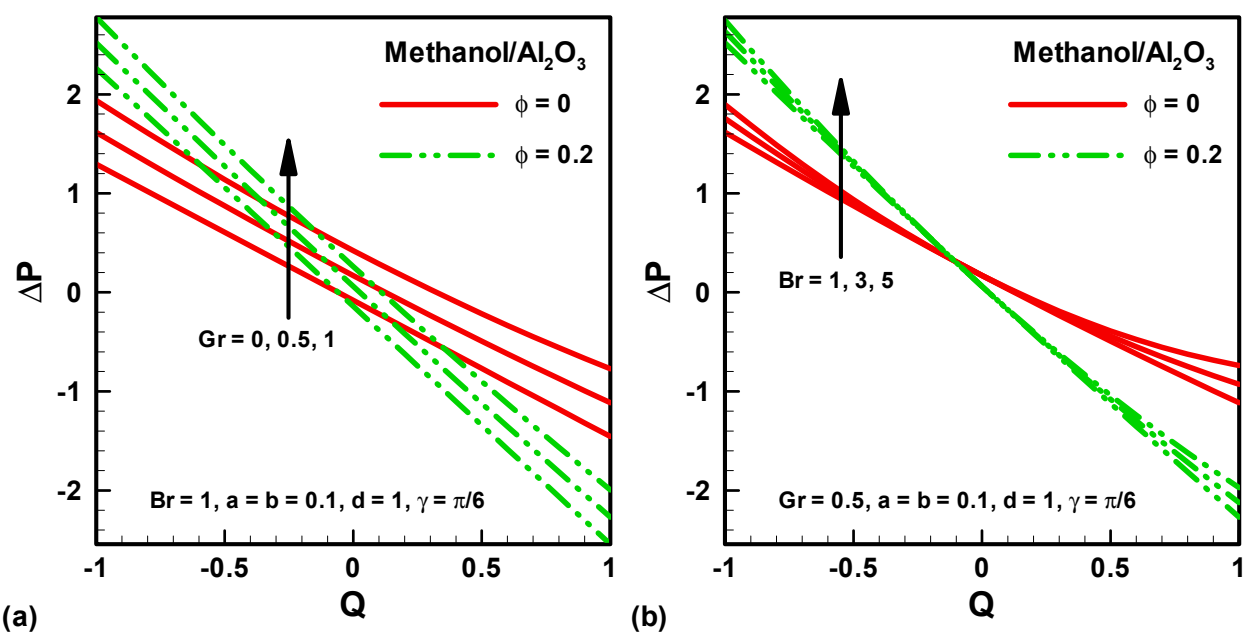

Figure 3. The pressure rise $\Delta \mathrm{P}$ versus the flow rate $Q$ for different values of (a) the Grashof number $G r$; (b) the Brinkman number $\mathrm{Br}$.
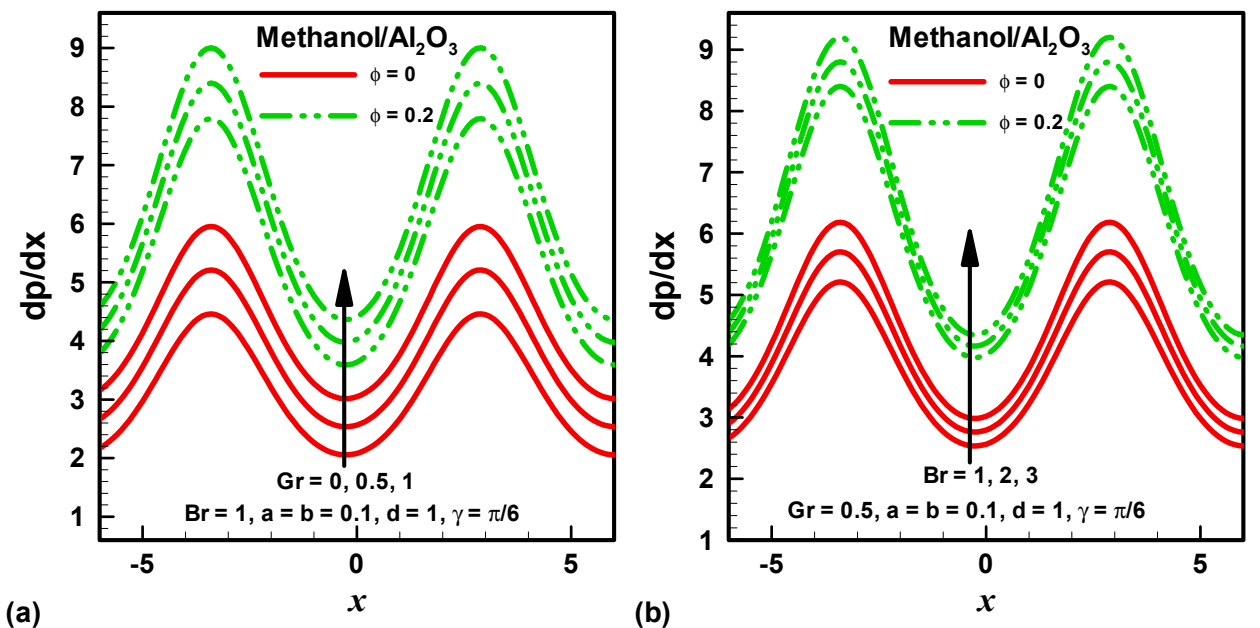

Figure 4. The pressure gradient $d p / d x$ versus $x$ for different values of (a) the Grashof number $G r$; (b) the Brinkman number $\mathrm{Br}$.
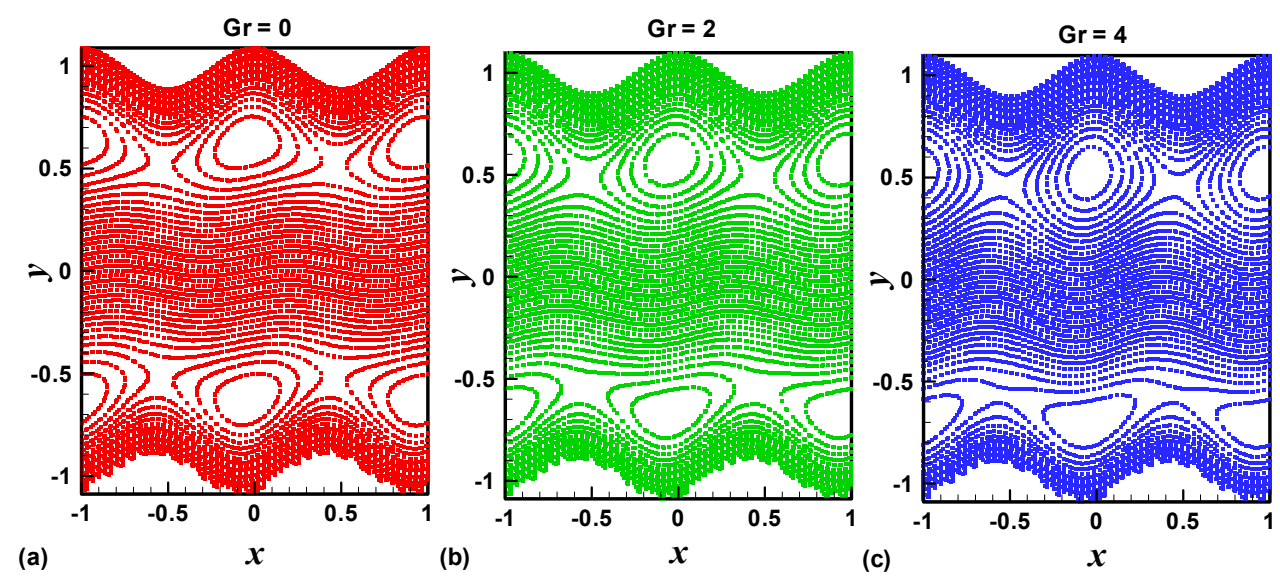

Figure 5. The stream lines for different values of the Grashof number (a) $G r=0$; (b) $G r=2$; (c) $G r=4.0$. 

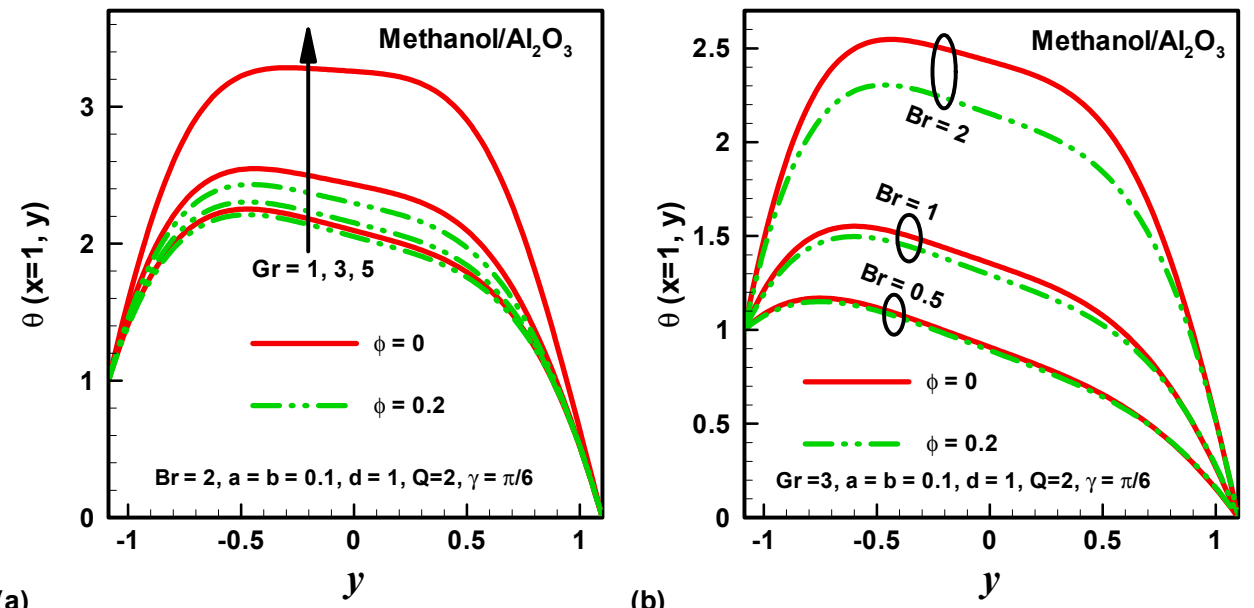

Figure 6. The temperature profile $\theta$ versus $y$ for different values of (a) the Grashof number $G r$; (b) the Brinkman number $\mathrm{Br}$.
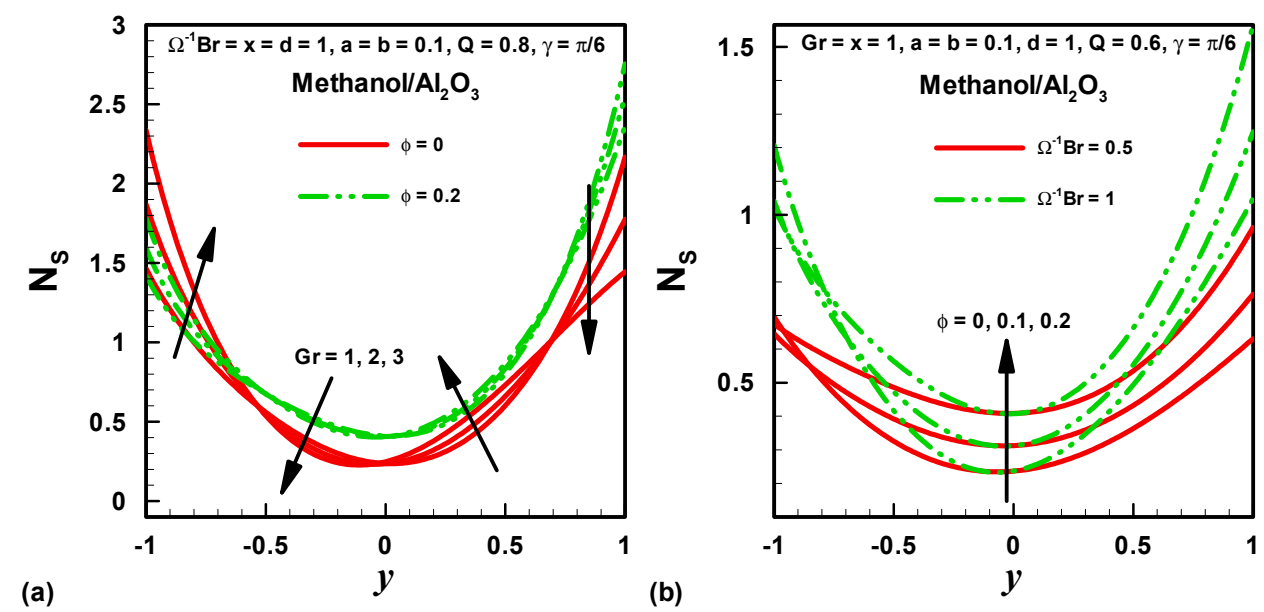

Figure 7. Entropy generation number $\mathrm{N}_{\mathrm{S}}$ versus $y$ for different values of (a) the Grashof number Gr; (b) the viscous dissipation group parameter $B r \Omega^{-1}$.
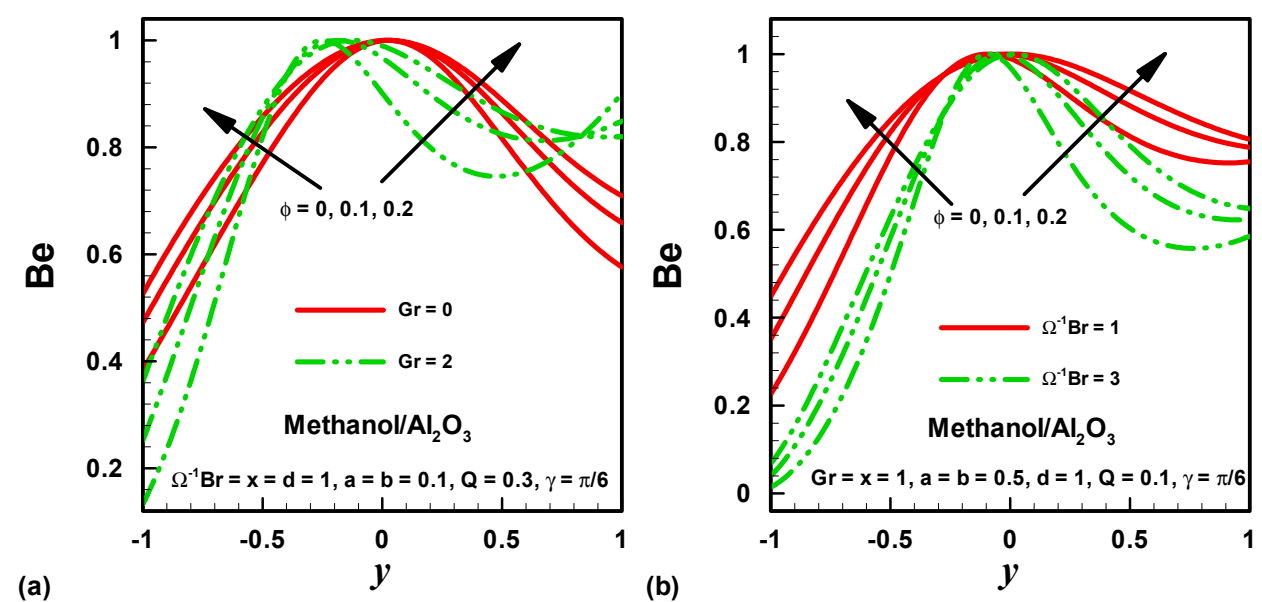

Figure 8. The Bejan number Be versus $y$ for different values of (a) the Grashof number Gr; (b) the viscous dissipation parameter $B r \Omega^{-1}$. 
Acknowledgments: Authors would like to acknowledge and express their gratitude to the United Arab Emirates University, Al Ain, UAE for providing the financial support with Grant No. 31S240-UPAR (2) 2016. The authors also want to acknowledge with thanks the Deanship of Scientific Research (DSR) at Majmaah University, Majmaah Saudi Arabia for technical and financial support.

Author Contributions: Muhammad Qasim and Zafar Hayat Khan formulated the problem. Muhammad Qasim and Ilyas Khan solved the problem. Zafar Hayat Khan and Qasem M. Al-Mdallal computed the results. All the authors equally contributed in writing and proofreading the paper.

Conflicts of Interest: The authors declare no conflict of interest.

\section{References}

1. Latham, T.W. Fluid Motion in a Peristaltic Pump. Master's Thesis, Massachusetts Institute of Technology, Cambridge, MA, USA, 1966.

2. Shapiro, A.H.; Jaffrin, M.Y.; Weinberg, S.L. Peristaltic pumping with long wave lengths at low Reynolds numbers. J. Fluid Mech. 1969, 37, 799-825. [CrossRef]

3. Mekheimer, K.S. Peristaltic flow of blood under the effect of magnetic field in a non-uniform channels. Appl. Math. Comput. 2004, 153, 763-777. [CrossRef]

4. Mekheimer, Kh.S.; Elmaboud, Y.A. The influence and heat transfer and magnetic field on peristaltic transport of a magnetic field on peristaltic transport of Newtonian fluid in a vertical annulus: Application of an endoscope. Phys. Lett. A 2008, 372, 1657-1665. [CrossRef]

5. Srinivas, S.; Kothandapani, M. Peristaltic transport in an asymmetric channel with heat transfer-A note. Int. Commun. Heat Mass Transf. 2008, 35, 514-522. [CrossRef]

6. Kothandapani, M.; Srinivas, S. Peristaltic transport of a Jeffrey fluid under the effect of magnetic field in an asymmetric channel. Int. J. Non-Linear Mech. 2008, 43, 915-924. [CrossRef]

7. Srinivas, S.; Muthuraj, R. Effects of chemical reaction and space porosity on MHD mixed convective flow in a vertical asymmetric channel with peristalsis. Math. Comput. Model. 2011, 54, 1213-1227. [CrossRef]

8. Noreen, S.; Hayat, T.; Alsaedi, A. Magnetohydrodynamic peristaltic flow of a pseudoplastic fluid in a curved channel. Zeitschrift Naturforschung A 2010, 29, 387-394. [CrossRef]

9. Srinivas, S.; Gayathri, R.; Kothandapani, M. Mixed convective heat and mass transfer in an asymmetric channel with peristalsis. Commun. Nonlinear Sci. Numer. Simul. 2011, 16, 1845-1862. [CrossRef]

10. Akbar, N.S.; Nadeem, S.; Lee, C. Peristaltic flow of a Prandtl fluid model in an asymmetric channel. Int. J. Phys. Sci. 2012, 7, 687-695.

11. Choi, S.U.S. Enhancing thermal conductivity of fluids with nanoparticles. In Proceedings of the 1995 ASME International Mechanical Engineering Congress and Exposition, San Francisco, CA, USA, 12-17 November 1995; pp. 99-105.

12. Minkowycz, W.J.; Sparrow, E.M.; Abraham, J.P. Nanoparticle Heat Transfer and Fluid Flow; CRC Press: Boca Raton, FL, USA, 2013.

13. Akbar, N.S.; Nadeem, S. Endoscopic effects on peristaltic flow of a nanofluid. Commun. Theor. Phys. 2011, 56, 761-768. [CrossRef]

14. Akbar, N.S.; Nadeem, S.; Hayat, T.; Hendi, A.A. Peristaltic flow of a nanofluid with slip effects. Meccanica 2012, 47, 1283-1294. [CrossRef]

15. Akbar, N.S.; Nadeem, S. Peristaltic flow of a nanofluid in a non-uniform tube. Heat Mass Transf. 2012, 48, 451-459. [CrossRef]

16. Shehzad, S.A.; Abbasi, F.M.; Hayat, T.; Alsaadi, F. Model and comparative study for peristaltic transport of water based nanofluids. J. Mol. Liq. 2015, 209, 723-728. [CrossRef]

17. Tripathi, D.; Anwar Bég, O. Mathematical modelling of peristaltic transport of nanofluids. Int. J. Heat Mass Transf. 2014, 70, 61-70. [CrossRef]

18. Anwar Bég, O.; Tripathi, D. Mathematica simulation of peristaltic pumping with double-diffusive convection in nanofluids: A bio-nano-engineering model. Proc. Inst. Mech. Eng. Part N 2012, 225, 99-114.

19. Akbar, N.S. Heat transfer and carbon nano tubes analysis for the peristaltic flow in a diverging tube. Meccanica 2015, 50, 39-47. [CrossRef]

20. Akbar, N.S.; Khan, Z.H. Metachoronical beating of cilia for nanofluid with Newtonian heating. J. Magn. Magn. Mater. 2015, 381, 235-242. [CrossRef] 
21. Noreen, S.; Qasim, M.; Khan, Z.H. MHD pressure driven flow of nanofluid in curved channel. J. Magn. Magn. Mater. 2015, 393, 490-497. [CrossRef]

22. Ebaid, A.; Aly, E.H. Exact Analytical Solution of the Peristaltic Nanofluids Flow in an Asymmetric Channel with Flexible Walls and Slip Condition: Application to the Cancer Treatment. Comput. Math. Methods Med. 2013, 8, 825376. [CrossRef] [PubMed]

23. Naterer, G.F.; Camberos, J.A. Entropy Based Design and Analysis of Fluids Engineering Systems; CRC Press: Boca Raton, FL, USA, 2008.

24. Bejan, A. Entropy Generation through Heat and Fluid Flow; Willey: New York, NY, USA, 1982.

25. Bejan, A. Entropy Generation Minimization; CRC Press: New York, NY, USA, 1996.

26. Makinde, D.; Osalusi, E. Second law analysis of laminar flow in a channel filled with saturated porous media. Entropy 2005, 7, 148-160. [CrossRef]

27. Makinde, D. Entropy generation analysis for variable viscosity channel flow with non-uniform wall temperature. Appl. Energy 2008, 85, 384-393. [CrossRef]

28. Makinde, D.; Eegunjobi, A.S.; Tshehla, M.S. Thermodynamics analysis of variable viscosity Hydromagnetic Couette flow in a rotating system with Hall effects. Entropy 2015, 17, 7811-7826. [CrossRef]

29. Golra, R.S.R. Second law analysis of mixed convection in a laminar, non-Newtonian fluid flow through a vertical channel. ISRN Appl. Math. 2011, 2011, 287691. [CrossRef]

30. Rashidi, M.M.; Mohmud, S.; Freidoonimehr, N.; Rostami, B. Analysis of entropy generation in an MHD flow over a rotating porous disk with variable physical properties. Int. J. Exergy 2015, 16, 481-503. [CrossRef]

31. Arikodlu, A.; Ozkol, I.; Komurgoz, G. Effects of slip on entropy generation in a single rotating disk in MHD flow. Appl. Energy 2008, 85, 1225-1236. [CrossRef]

32. Afridi, M.I.; Qasim, M.; Khan, I.; Sharidan, S.; Alshomrani, A.S. Entropy generation in magnetohydrodynamic mixed convection flow over an inclined stretching sheet. Entropy 2017, 19, 10. [CrossRef]

33. Khan, A.; Khan, I.; Ali, F.; Shafie, S. A note on entropy generation in MHD flow over a vertical plate embedded in a porous medium with arbitrary shear stress and ramped temperature. J. Porous Media 2016, 19, 175-187. [CrossRef]

34. Rashidi, M.M.; Abelman, S.; Mehr, N.F. Entropy generation in steady MHD flow due to a rotating porous disk in a nanofluid. Int. J. Heat Mass Transf. 2013, 62, 515-525. [CrossRef]

35. Souidi, F.; Ayachi, K.; Benyahia, N. Entropy generation rate for peristaltic pump. J. Non-Equilib. Thermodyn. 2009, 34, 171-194. [CrossRef]

36. Akbar, N.S. Entropy generation analysis for a CNT suspension nanofluid in plumb ducts with peristalsis. Entropy 2015, 17, 1411-1424. [CrossRef]

37. Akbar, N.S.; Raza, M. Peristaltic flow with thermal conductivity of $\mathrm{H}_{2} \mathrm{O}+\mathrm{Cu}$ nanofluid and entropy generation. Results Phys. 2015, 5, 115-124. [CrossRef]

38. Rashidi, M.M.; Bhatti, M.M.; Abbas, M.A.; Ali, M.E.S. Entropy generation on MHD blood flow of nanofluid due to peristaltic waves. Entropy 2016, 18, 117. [CrossRef]

39. Abbas, M.A.; Bai, Y.; Rashidi, M.M.; Bhatti, M.M. Analysis of entropy generation in the flow of peristaltic nanofluids in channels with compliant walls. Entropy 2016, 18, 90. [CrossRef]

40. Hsiao, K.L. Stagnation electrical MHD nanofluid mixed convection with slip boundary on a stretching Sheet. Appl. Therm Eng. 2016, 98, 850-861. [CrossRef]

41. Hsiao, K.-L. MHD mixed convection of viscoelastic fluid over a stretching sheet with ohmic dissipation. J. Mech. 2008, 24, 29-34. [CrossRef]

42. Hsiao, K.L. Numerical solution for Ohmic Soret-Dufour heat and mass mixed convection of viscoelastic fluid over a stretching sheet with multimedia physical features. J. Aerosp. Eng. 2016, 30. [CrossRef]

43. Hayat, T.; Ahmed, B.; Abbasi, F.M.; Ahmad, B. Mixed convective peristaltic flow of carbon nanotubes submerged in water using different thermal conductivity models. Comput. Methods Programs Biomed. 2016, 135, 141-150. [CrossRef] [PubMed]

44. Noreen, S.; Rashidi, M.M.; Qasim, M. Blood flow analysis with considering nanofluid effects in vertical channel. Appl. Nanosci. 2017, 7, 193-199. [CrossRef]

(C) 2017 by the authors. Licensee MDPI, Basel, Switzerland. This article is an open access article distributed under the terms and conditions of the Creative Commons Attribution (CC BY) license (http:/ / creativecommons.org/licenses/by/4.0/). 